Louisiana State University

LSU Digital Commons

Faculty Publications

Department of Chemistry

$5-1-2012$

\title{
Experimental reaction-driven liquid film fingering instability
}

\author{
L. A. Riolfo \\ Université libre de Bruxelles (ULB) \\ J. Carballido-Landeira \\ Université libre de Bruxelles (ULB) \\ C. O. Bounds \\ Louisiana State University \\ J. A. Pojman \\ Louisiana State University \\ S. Kalliadasis \\ Imperial College London
}

See next page for additional authors

Follow this and additional works at: https://digitalcommons.Isu.edu/chemistry_pubs

\section{Recommended Citation}

Riolfo, L., Carballido-Landeira, J., Bounds, C., Pojman, J., Kalliadasis, S., \& De Wit, A. (2012). Experimental reaction-driven liquid film fingering instability. Chemical Physics Letters, 534, 13-18. https://doi.org/ 10.1016/j.cplett.2012.03.024

This Article is brought to you for free and open access by the Department of Chemistry at LSU Digital Commons. It has been accepted for inclusion in Faculty Publications by an authorized administrator of LSU Digital Commons.

For more information, please contact ir@lsu.edu. 


\section{Authors}

L. A. Riolfo, J. Carballido-Landeira, C. O. Bounds, J. A. Pojman, S. Kalliadasis, and A. De Wit 


\title{
Experimental reaction-driven liquid film fingering instability
}

\author{
L.A. Riolfo ${ }^{\mathrm{a}, *}$, J. Carballido-Landeira $^{\mathrm{a}, \mathrm{c}}$, C.O. Bounds ${ }^{\mathrm{b}}$, J.A. Pojman ${ }^{\mathrm{b}}$, S. Kalliadasis ${ }^{\mathrm{d}}$, A. De Wit ${ }^{\mathrm{a}}$ \\ a Nonlinear Physical Chemistry Unit, Service de Chimie Physique et Biologie Théorique, Faculté des Sciences CP 231, Université Libre de Bruxelles (ULB), 1050 Brussels, Belgium \\ ${ }^{\mathrm{b}}$ Department of Chemistry, Louisiana State University, 211 Choppin Hall, Baton Rouge, LA 70803-1804, United States \\ ${ }^{\mathrm{c}}$ Group of Nonlinear Physics, Department of Physics, University of Santiago de Compostela, E-15782 Santiago de Compostela, Spain \\ ${ }^{\mathrm{d}}$ Department of Chemical Engineering, Imperial College London, London SW7 2AZ, United Kingdom
}

\section{A R T I C L E I N F O}

\section{Article history:}

Received 31 October 2011

In final form 2 March 2012

Available online 17 March 2012

\begin{abstract}
A B S T R A C T
Reaction-driven pattern formation at the interface between two thin liquid films is studied experimentally on a vertical substrate when two organic liquids, an acrylate and a secondary amine, respectively, are put in contact. On a clean glass plate, the pure liquids spread without any instability and no film deformation is observed. On the contrary, if the substrate is pre-wetted with the amine followed by deposition of acrylate on the amine, the two liquids react at the edge of the spreading acrylate film. Fractal patterns are observed to develop at the nominal contact line. No instability is obtained in the reverse reactive case of amine deposited on acrylate. A qualitative explanation of the observed reaction-driven patterns is given in terms of solutal Marangoni effects induced by differences in local values of surface tension.
\end{abstract}

Crown Copyright $\odot 2012$ Published by Elsevier B.V. All rights reserved.

\section{Introduction}

The dynamics of thin liquid films and droplet spreading on solid surfaces have been intensively studied due to their importance not only in technological applications, from oil recovery [1] and drainage of water from highways [2] to metal or glass anti-corrosive coating or lubrication [3], but also in natural phenomena, e.g. deposition and repellency of liquid droplets on plant leaves [4,5]. The spontaneous spreading of thin liquid films under capillary forces alone is typically a slow process $[3,6]$. Theoretical and experimental studies have shown that in the case of forced spreading induced by a body force, such as centrifugal $[7,8]$ or gravitational forces $[9,10]$, the liquid film can undergo fingering instabilities.

It has also been shown that interfacial Marangoni stresses can be the source of unstable driven flows at the edges of films or droplets. The local differences in surface tension can be induced either by a temperature gradient in the substrate $[6,11]$, by differential evaporation in two-component mixtures $[12,13]$ or by differences in surfactant concentration at a liquid-gas interface [14-18]. The interaction between thin liquid film dynamics and chemical reactions has been studied as well in numerous works which show that chemical reactions can destabilize the film free surface by inducing solutal and/or thermal Marangoni stresses (e.g. [19-25]).

In fact, as some of these studies have demonstrated, chemical reactions can induce complex fluid motion and pattern formation on the surface of a film. They can also induce macroscopic droplet

\footnotetext{
* Corresponding author. Fax: +32 26505767 .

E-mail addresses: lriolfo@ulb.ac.be (L.A. Riolfo), s.kalliadasis@imperial.ac.uk (S Kalliadasis), adewit@ulb.ac.be (A. De Wit).
}

motion. For example, adsorption (or desorption) chemical reactions in a droplet on a partially wetting solid substrate induce wettability gradients and provide the driving force for droplet motion. This problem has also received considerable attention and has been studied both theoretically [26,27] and experimentally [28-30].

In this Letter we report a new example of a thin-film instability due to a chemical reaction. The instability occurs when a liquid film of a secondary amine, say A, spreads over a glass substrate coated by a thin film of acrylate, say $B$. The production at the contact zone between $A$ and $B$ of a product $C$, via the simple reaction $A+B \rightarrow C$, yields a solutal Marangoni effect responsible for the developed instability. On the other hand, no instability is obtained if either one of the pure reactant liquids spreads over a clean glass or if a film of B spreads over glass precoated with A.

The structure of the article is as follows. We first describe the working fluids and the experimental set-ups. We then outline our experimental observations followed by a plausible explanation on the instability mechanism. We close with conclusions and perspectives.

\section{Experimental system}

\subsection{Liquids and chemical reaction}

The experiments were carried out using a secondary amine and an acrylate which are miscible and react to produce a tertiary amine. We specifically use dihexylamine $\left(\mathrm{C}_{12} \mathrm{H}_{27} \mathrm{~N}-97 \%\right.$ - Sigma Aldrich, Molecular Weight MW $=185)$ and hexyl acrylate $\left(\mathrm{C}_{9} \mathrm{H}_{16} \mathrm{O}_{2}-98 \%-\right.$ Sigma Aldrich, $\mathrm{MW}=156)$. The production of a tertiary amine $\left(\mathrm{C}_{21} \mathrm{H}_{43} \mathrm{NO}_{2}, \mathrm{MW}=341\right)$ from these two reactants is a 'Michael 
Table 1

Physical properties of the reactants A (dihexylamine), B (hexyl acrylate) and of the product C (hexyl acrylate).

\begin{tabular}{llll}
\hline Property & A & B & C \\
\hline Viscosity $(\mathrm{mPa} \mathrm{s})$ & 0.6 & 10 & 2.3 \\
Density at $25^{\circ} \mathrm{C}\left(\mathrm{g} / \mathrm{cm}^{3}\right)$ & 0.80 & 0.88 & 0.80 \\
Surface tension $($ dyne $/ \mathrm{cm})$ & 27.2 & 28.0 & - \\
Contact angle $\left({ }^{\circ}\right)$ & $<5$ & $<5$ & $<5$ \\
\hline
\end{tabular}

Table 2

Contact angles of the A-C and B-C mixtures at different molar fractions of $\mathrm{C}$.

\begin{tabular}{lll}
\hline Molar fraction $x_{\mathrm{C}}$ & $\begin{array}{l}\mathrm{A}-\mathrm{C} \\
\left({ }^{\circ}\right.\end{array}$ & $\begin{array}{l}\mathrm{B}-\mathrm{C} \\
\left({ }^{\circ}\right)\end{array}$ \\
\hline 0.25 & $<5$ & $<5$ \\
0.50 & 21.7 & $<5$ \\
0.75 & $<5$ & $<5$ \\
\hline
\end{tabular}

reaction' [31,32]. This reaction proceeds through several steps but can be summed up as a simple A $+B \rightarrow C$ scheme, where $A$ and $B$ are dihexylamine and hexyl acrylate, respectively, while $C$ is the tertiary amine. Pertinent data on the physico-chemical properties of these liquids are given in Table 1 while the contact angles of the $\mathrm{A}-\mathrm{C}$ and $\mathrm{B}-\mathrm{C}$ mixtures as functions of the molar fraction of $\mathrm{C}$ are given in Table 2. Some of these values, such as contact angles of all species, the contact angles of the $\mathrm{A}-\mathrm{C}$ and $\mathrm{B}-\mathrm{C}$ mixtures, and the density and viscosity of $C$, where measured by ourselves. The remaining values were obtained from [33]. Using the data in the table and a typical velocity $U$ of $8 \times 10^{-3} \mathrm{~cm} / \mathrm{s}$ (obtained from the experiment shown in Figure 4), a typical capillary number value is $\mathrm{Ca}=\mu_{\mathrm{B}} U / \sigma_{\mathrm{B}} \sim 3 \times 10^{-5}$, while using $L=0.5 \mathrm{~cm}$, a typical Reynolds number value is $\operatorname{Re}=\mu_{\mathrm{B}} L U /$ $\sigma_{\mathrm{B}} \sim 3.5 \times 10^{-2}$. Hence, we are in a regime where inertia is negligible and capillarity dominates. Also, by taking into account that in general the diffusion coefficient is inversely related to the molecular weight, it can be assumed that the liquid-liquid diffusion coefficients are such that $D_{B}>D_{A}>D_{C}$.

Finally, we note that $A, B$ and $C$ all have contact angles $<5^{\circ}$ and hence they are almost completely wetting for the substrate used in the experiments. The same for the $\mathrm{B}-\mathrm{C}$ mixture while the $\mathrm{A}-\mathrm{C}$ mixture is almost completely wetting for $x_{C}=0.25$ (i) and $x_{C}=0.75$ (iii) but it is non-wetting for $x_{C}=0.50$ (ii). This behavior can be explained as follows: as the pure $A$ and $C$ have contact angles $<5^{\circ}$, when $C$ is not in a high-enough concentration, or when the concentration of $C$ is sufficiently high, the contact angle of the mixture is close to that of pure A or pure $C$, respectively. It also seems, that A and $\mathrm{C}$ interact in a non-trivial fashion as indicated by the fact that

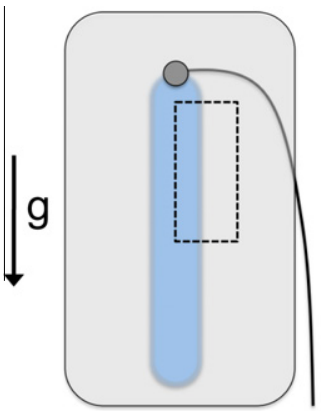

(a)

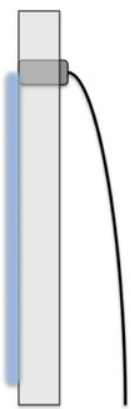

(b)
I the contact angle of the mixture changes with $C$ and such that in case (ii) it has the maximum possible difference from the contact angles in cases (i) and (iii) (it is reasonable to assume that this interaction is maximum when the molar fractions of $\mathrm{A}$ and $\mathrm{C}$ are equal). We shall return to this point later.

\subsection{Experimental set-ups}

Two different experimental set-ups were used to study the reacting liquid film dynamics. One experimental device consists of a rectangular glass plate $10 \mathrm{~cm}$ long and $5 \mathrm{~cm}$ wide, cleaned with distillate water and dried with pressurized air, oriented vertically with a hole in the top center through which a drop of approximately $0.1 \mathrm{ml}$ of liquid is injected via a tube connected to a syringe, as sketched on Figure 1-I. The liquid droplet slides down over the substrate because of gravity, leaving a trail of liquid with a thickness of $100 \mu \mathrm{m}$ or less in its path.

The other experimental set-up consists of a glass plate vertically oriented, but supported on a clean glass base. A drop of approximately $0.3 \mathrm{ml}$ of liquid is deposited, as shown in the sketch of Figure 1-II, on the lower part of the vertically oriented glass and at the edge side in contact with the base.

To visualize the dynamics in both cases, the downward motion of the droplet on set-up I or its ascending spreading on set-up II, a shadowgraph technique is used since both reactant liquids as well as the product are transparent. The experiments are recorded with a video camera $(4400 \times 3000$ pixels $)$ at given time intervals.

\section{Experimental results}

\subsection{Non reactive gliding drop}

When a drop of either A or B liquid is injected and slides down on the vertical clean glass plate, no instability is observed at the edges of the liquid film left in the path of the droplet. Both the secondary amine A and acrylate B eventually drain out of the glass. In both cases, the edge of the thin film does not undergo fingering and no instability is observed. The images in Figure 2 correspond to the region marked as a dashed rectangle in Figure 1a. Here, all liquids are transparent and the darker zones correspond to changes in the refractive index due to changes in the curvature, as in the thicker liquid part of the droplet tip for instance (Figure 2a-I and b-I).

\subsection{Reactive gliding drop}

To see whether a chemical reaction between the amine and the acrylate can modify the dynamics, we next performed experiments

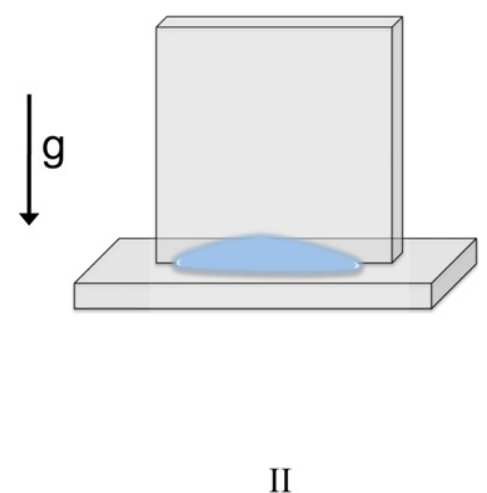

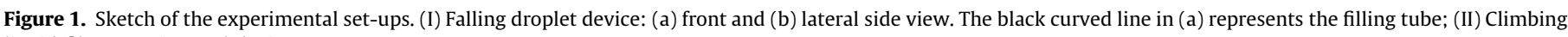
liquid-film experimental device. 


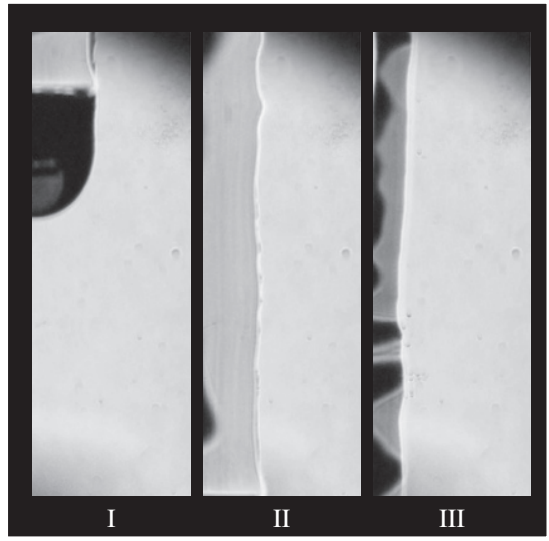

(a)

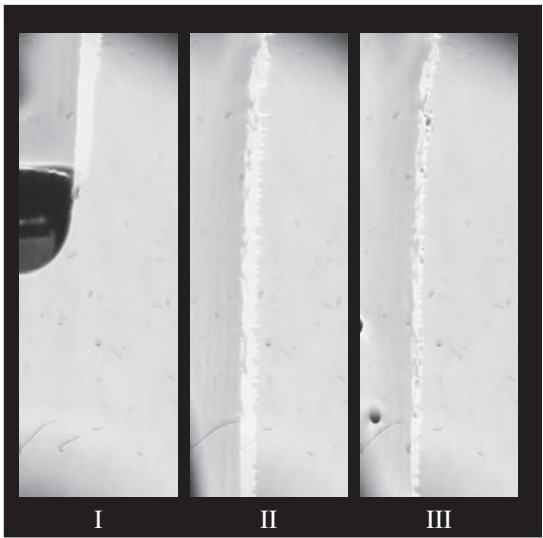

(b)

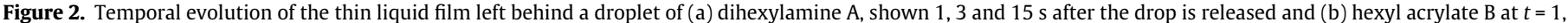
12 and $60 \mathrm{~s}$ after drop release. Field of view: $0.8 \mathrm{~cm} \times 2.5 \mathrm{~cm}$.

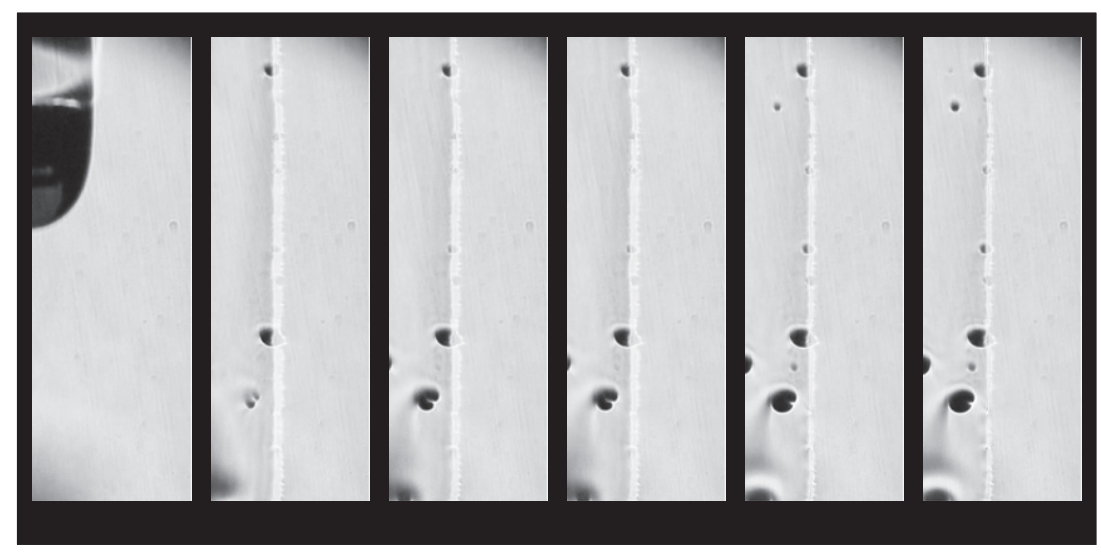

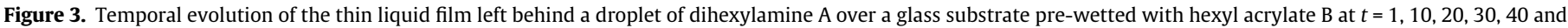
$50 \mathrm{~s}$. Field of view: $0.8 \mathrm{~cm} \times 2.5 \mathrm{~cm}$.

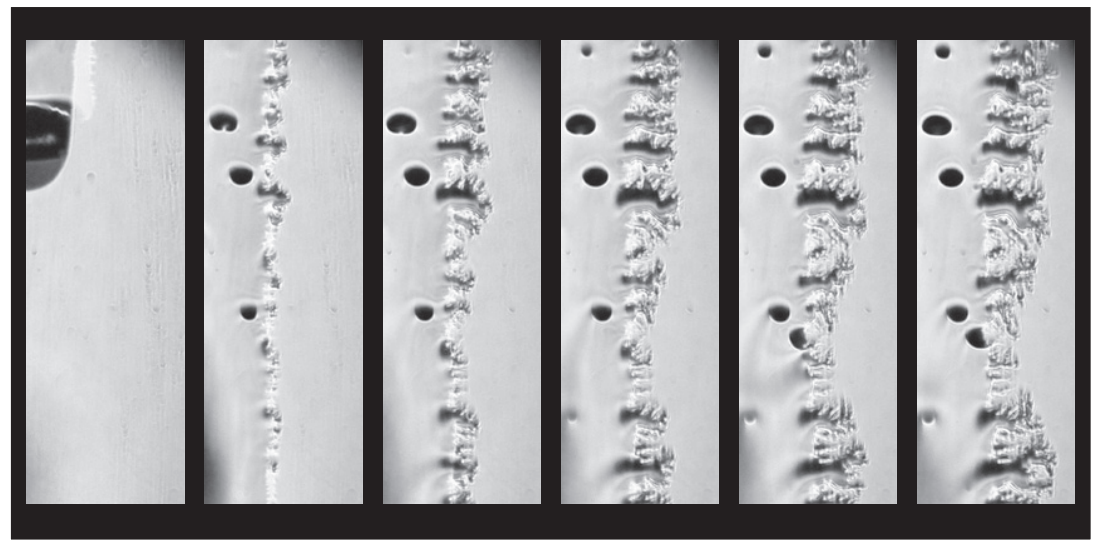

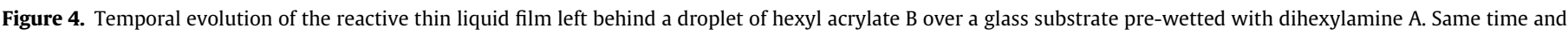
field of view as in Figure 3.

where a droplet of one of the reactants glides down on the glass pre-wetted by a thin film of the other reactant. If hexyl acrylate $B$ pre-coats the glass plate, and a droplet of dihexylamine A rolls down on top of it, the amine film remains on the acrylate, and neither spreads nor drains, as shown in Figure 3. The edge of the film remains straight, with no deformation for at least $3 \mathrm{~min}$. This is in contrast to the drainage behavior observed on the clean glass (Figure 2a).

In the reverse case, when the amine A pre-coats the glass and a droplet of acrylate B slides down on it, the dynamics is drastically 


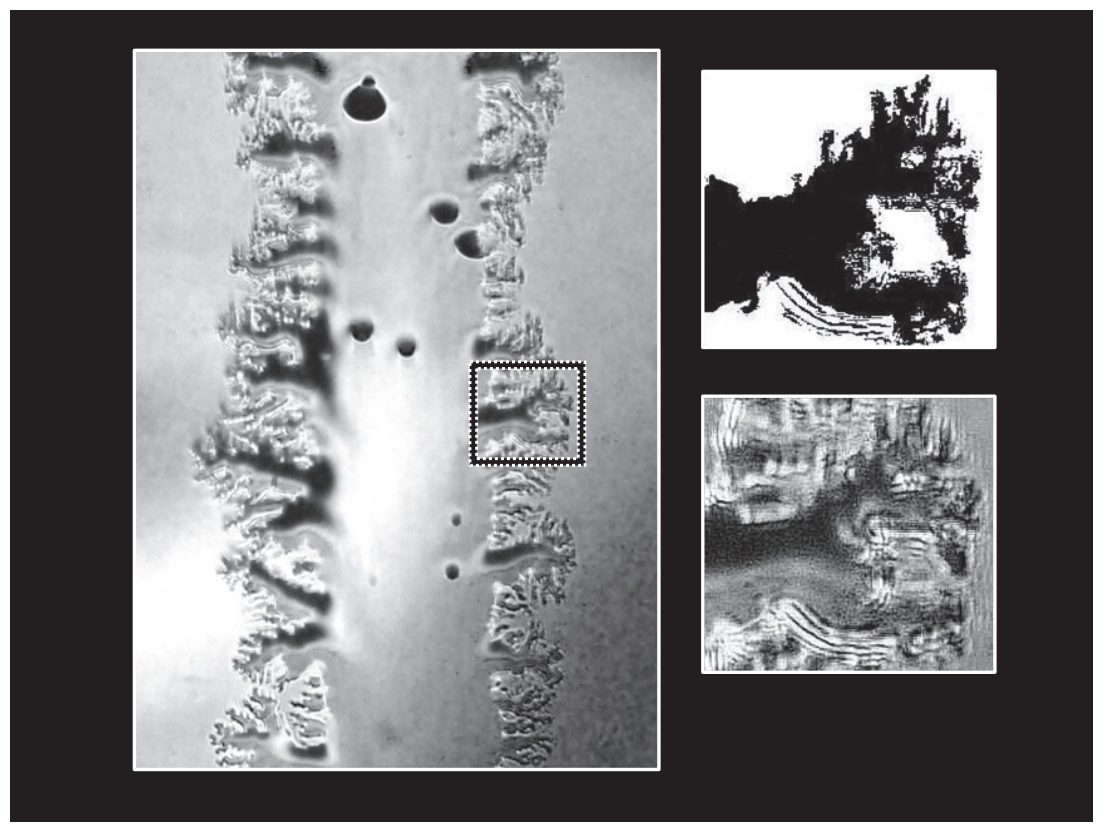

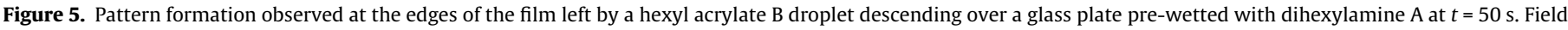

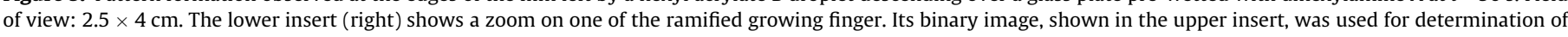
the fractal dimension.

different (Figure 4)): the edges of the film deform into fractal-like fingers and vivid ramification is observed. These fractal structures grow in time perpendicularly to the edges of the acrylate film, towards the pre-spread amine. The fractal dimension measured on an isolated fractal branch [15] (using a box-counting method) once the instability is fully developed ( $50 \mathrm{~s}$.) is $D_{f}=1.56$ (Figure 5). The fractal dimension of this reactive fingering is slightly smaller than the one found for non-reactive fingering with surfactants, typically ranging between $D_{f}=1.7$ and $1.8[15,17]$.

\subsection{Ascending reactive liquid-film}

When a droplet of either one of the reactants is deposited on the lower side of a clean, vertically oriented glass (Figure 1-II) no liquid rise on the substrate is observed. The liquid remains on the glass base, even though both hexyl acrylate B and dihexylamine A almost completely wet the glass: wetting is not sufficiently strong to work against gravity and make B or A climb up.

However, when a droplet of hexyl acrylate B (of approximately $0.3 \mathrm{ml}$ ) is deposited at the bottom side of a glass plate pre-wetted with dihexylamine A, a liquid film of B rises as shown in Figure 6. While acrylate climbs on the pre-wetted substrate and reaction occurs with the amine, the ascending front deforms into a strongly ramified fingering pattern. The observed patterns are more compact than those at the edges of the film left by the sliding acrylate droplet over the glass substrate pre-wetted with dihexylamine. No isolated branches can be distinguished, but a thin layer of liquid seems to be present, pulling a thicker liquid film behind it.

\section{Discussion}

From the above observations it is evident that the instability occurs only when the substrate is prewetted with A and not with $B$. This suggests that thermal effects are not the source of the instability as the enthalpy of reaction and the light source are the same in both experiments ( $\mathrm{A}$ on top of $\mathrm{B} v s \mathrm{~B}$ on top of $\mathrm{A}$ ). Evaporation effects are also comparable in both cases, since both reactants have similar vapor pressure at room temperature (Hexyl acrylate $=0.51 \mathrm{~mm} \mathrm{Hg}$ at $25^{\circ} \mathrm{C}$; Dihexylamine $=0.463 \mathrm{~mm} \mathrm{Hg}$ at $25^{\circ} \mathrm{C}$ ). The instability mechanism can therefore be conjectured to be rather due to solutal Marangoni effects as follows.

Let us assume that locally (in the reaction zone) the molar fraction of $\mathrm{C}$ in the A-C mixture does not exceed 50\%. In general, it is accepted that for a surfactant solution the surface tension of the solution will be reduced with surfactant concentration (until the 'critical micelle concentration'). The link between surface tension and contact angle is also evident from the Young's equation. (Of course, surface tension is a property of the fluids, while the contact angle is a property of the fluid-solid pair. But if we fix the solid as in the experiments here, the contact angle becomes a property of the fluid only.) By the same reasoning, as the concentration of $C$ in the $\mathrm{C}-\mathrm{A}$ mixture increases, the contact angle of $\mathrm{C}-\mathrm{A}$ increases (Table 2) and the surface tension of $\mathrm{C}-\mathrm{A}$ should also increase (after all, the fluid changes and this should impact not just on the contact angle but also on the other properties of the fluid, such as surface tension).

Hence $C$ acts as an 'anti-surfactant' on A. How about the influence of $C$ on $A$ ? The chemical structure of the different species suggests that $C$ can hydrogen bond with oxygen in $B$ and nitrogen in A. But (a) the $\mathrm{O}-\mathrm{H}$ bond is stronger to the $\mathrm{N}-\mathrm{H}$ one and (b) $\mathrm{O}$ is more easily accessible in $B$. Hence, $C$ quite likely will act as a surface active agent on $B$, i.e. a surfactant, but the contact angle of pure $B$ is already $<5^{\circ}$ (Table 1), thus lowering the surface tension of $\mathrm{B}$ and the corresponding contact angle would not be an appreciable effect.

With $C$ as an anti-surfactant on A, a drop of B on top of a film of A should follow the Troian et al. [14] scenario where a drop of a solution mixture consisting of water and AOT spreads on clean water. But instead of a drop with surfactants on top of a film without surfactants, we have a drop of a fluid (effectively) without surfactants on top of a film with anti-surfactants. The resulting surface tension gradient is in the same direction with that in the Troian et al. problem and hence we expect a Marangoni-driven hydrodynamic instability at the spreading front of the drop similar to that observed in [14-16]. The mechanism for this instability was elucidated in a follow-up study by Troian et al. [34]. According to 


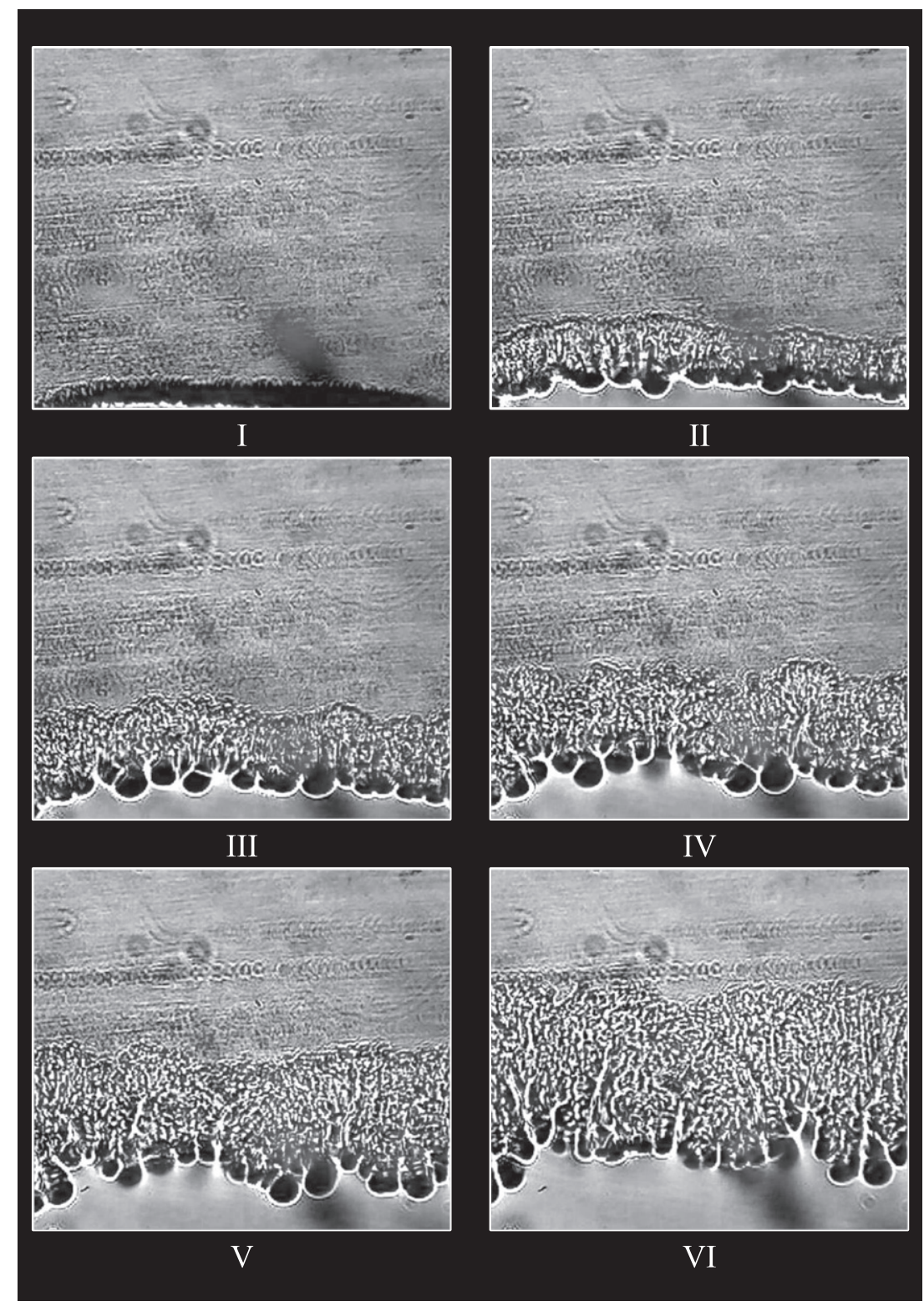

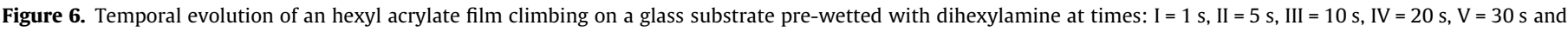
$\mathrm{VI}=60 \mathrm{~s}$. Field of view: $1 \times 1.2 \mathrm{~cm}$

these authors, the onset of fingering can be explained by analogy to other hydrodynamic fingering instabilities such as Saffman-Taylor, i.e. it is due to the 'mobility' effect: the average fluid velocity, say $u$ is proportional to the solute concentration gradient times a mobility factor, $h / \eta$, where $h$ is the local film thickness and $\eta$ is the fluid viscosity. An adverse mobility gradient then is present at the thin liquid region where the drop meets the film ahead which in turn retards fluid motion (induced by the surface-tension gradient) and surfactant there, thus causing fingering.

Assume now for simplicity that we have a drop of B in contact with the substrate and the drop has a film of $A$ at its front so that the reaction takes place at the lateral boundaries of the liquid film (but the proposed mechanism works also with a drop of fluid on top of a thin film of another fluid). We then have a B-A interface with $B, A$ occupying the left- and right-half of the domain, respectively as shown in Figure 7-I. As the concentration of A in C locally (in the reaction zone) increases, the contact angle of the C-A mixture increases. $\mathrm{C}-\mathrm{A}$ then should contract leaving space for $\mathrm{C}-\mathrm{B}$. As
$\mathrm{C}-\mathrm{A}$ contracts, the $\mathrm{B}-\mathrm{C}$ mixture will move towards $\mathrm{C}-\mathrm{A}$. This is because $B$ and A (a) are miscible and the overall fluid cannot 'break', (b) they react, and (c) B diffuses faster than A (The same mechanism should also be responsible for B climbing up a vertical plate prewetted with a film of A discussed earlier).

On the other hand, when the substrate is prewetted with $B$ and A flows on top of $B$, the situation is reversed (see Figure 7-II) and the instability is not observed: now the anti-surfactant concentration and mobility gradients are in the same direction.

Clearly, when this reactive fingering phenomenon occurs against gravity as in the case with the ascending reactive film experiment (Figure 6), the gravitational force opposes the Marangoni effect. In fact gravity now pulls the thicker developed liquid layer down. Therefore, isolated branches like those seen in the reactive droplet experiment are not observed. Once too much liquid is accumulated, gravity pulls it down towards the liquid droplet bulk, favoring the development of thinner film branches with a denser fractal pattern. Hence, the difference between the patterns 


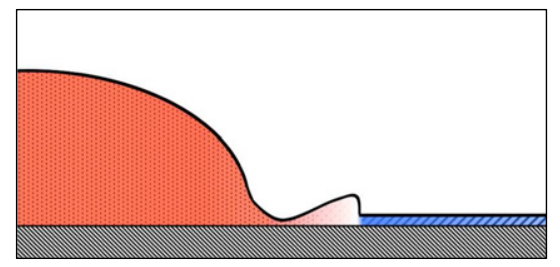

(I)

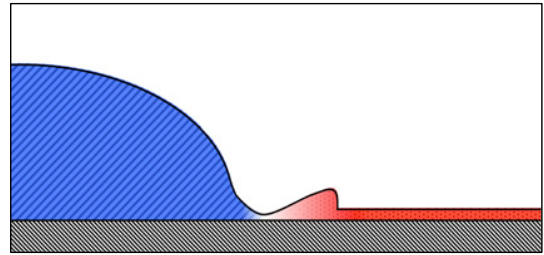

(II)

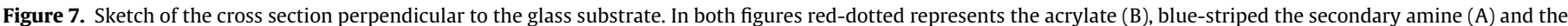

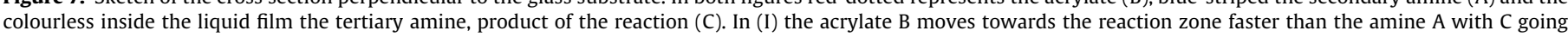

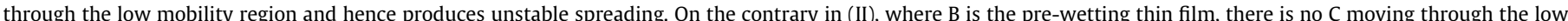

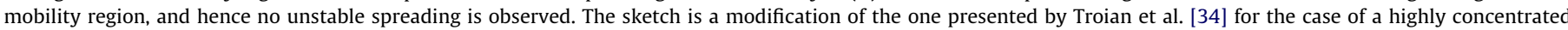

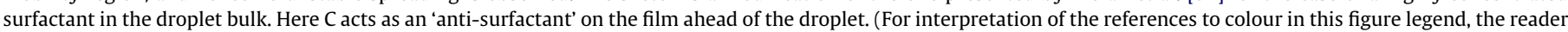
is referred to the web version of this article.)

observed in the sliding down drop experiment (Figure 4) and those in the ascending film one (Figure 6).

\section{Conclusion}

We have provided experimental evidence of chemically-driven hydrodynamic flows where the underlying properties of the reactants affect the properties of the developed patterns [35,36]. More specifically, we have presented a new chemically-driven fingering instability scenario where the edges of a thin film of a reactant deform into a fractal-like patten upon spreading over a vertical glass pre-wetted by a thin film of another reactant. Fingering is observed whenever B spreads over A and not in the reverse case. We conjectured that the instability is driven by a solutal Marangoni effect at the nominal contact line of a drop of B on top of a thin film of A.

We have also proposed a novel experimental configuration (sliding droplet) allowing for easily created flat thin film interfaces where gravity does not play any dominant role beyond fixing the initial configuration. Comparing the dynamics in this configuration with the one observed in the climbing liquid film elucidates the influence that gravity may have on reactive spreading of thin liquid films.

We hope that our results will motivate further studies on the influence of chemical reactions on hydrodynamic spreading and coating.

\section{Acknowledgements}

We are grateful to Dr. T. Dufour and Prof. F. Reniers for assistance with measuring contact angles and to Prof. Len Pismen for stimulating discussions. We acknowledge the financial support of EU-FP7 ITN Multiflow and FNRS.

\section{References}

[1] E. Bertrand, D. Bonn, H. Kellay, B. Binks, J. Meunier, Europhys. Lett. 55 (2001) 827.
[2] D. Bonn, J. Eggers, J. Meunier, E. Rolley, Rev. Mod. Phys. 81 (2009) 739.

[3] L. Legert, J.F. Joanny, Rep. Prog. Phys. 55 (1992) 431.

[4] V. Bergeron, D. Bonn, J.-Y. Martin, L. Vovelle, Nature 405 (2000) 772.

[5] V. Bergeron, C.R. Physique 4 (2003) 211.

[6] A.M. Cazabat, F. Heslot, S.M. Troian, P. Carles, Nature 346 (1990) 824

[7] F. Melo, J.-F. Joanny, S. Fauve, Phys. Rev. Lett. 63 (1989) 1958.

[8] N. Fraysse, G.M. Homsy, Phys. Fluids 6 (1994) 1491.

[9] H.E. Huppert, Nature 300 (1982) 427.

[10] S. Kalliadasis, J. Fluid Mech. 413 (2000) 355.

[11] J.M. Skotheim, U. Thiele, B. Scheid, J. Fluid Mech. 475 (2003) 1.

[12] X. Fanton, A.M. Cazabat, Langmuir 14 (1998) 2554.

[13] A.E. Hosoi, J.W.M. Bush, J. Fluid Mech. 442 (2001) 217

[14] S.M. Troian, X.L. Wu, S.A. Safran, Phys. Rev. Lett. 62 (1989) 1496.

[15] M. Cachile, M. Schneemilch, A. Hamraoui, A.M. Cazabat, Adv. Coll. Interf. Sci. 96 (2002) 59.

[16] M. Cachile, A.M. Cazabat, S. Bardon, M.P. Valignat, F. Vandenbrouck, Colloid Surface A: Physicochem. Eng. Aspects 159 (1999) 47.

[17] S.M. Troian, X.L. Wu, S.A. Safran, Phase transitions in soft condensed matter, in: T. Riste, D. Sherringto (Eds.), NATO ASI Series, vol. 211, Plenum Press, New York, 1989.

[18] M.R.E. Warner, R.V. Craster, O.K. Matar, J. Fluid Mech. 510 (2004) 169.

[19] A. De Wit, D. Gallez, C.I. Christov, Phys. Fluids 6 (1994) 3256.

[20] D. Gallez, A. De Wit, M. Kaufman, J. Coll. Interf. Sci. 180 (1996) 524.

[21] P.M.J. Trevelyan, S. Kalliadasis, Phys. Fluids 16 (2004) 3191.

[22] A. Pereira, P.M.J. Trevelyan, U. Thiele, S. Kalliadasis, Phys. Fluids 19 (2007) 112102.

23] A. Pereira, P.M.J. Trevelyan, U. Thiele, S. Kalliadasis, J. Eng. Math. 59 (2007) 207.

[24] A. Pereira, P.M.J. Trevelyan, U. Thiele, S. Kalliadasis, Eur. Phys. J. Special Top. 166 (2009) 121.

25] L.M. Pismen, Phys. Rev. E 81 (2010) 026307.

[26] U. Thiele, K. John, M. Bär, Phys. Rev. Lett. 93 (2004) 0278021.

[27] K. John, M. Bär, U. Thiele, Eur. Phys. J. E 18 (2005) 183.

[28] M.K. Chaudhury, G.M. Whitesides, Science 256 (1992) 5063.

[29] F.D. Dos Santos, T. Ondarcuhu, Phys. Rev. Lett. 75 (1995) 2972.

[30] S.-W. Lee, D.Y. Kwok, P.E. Laibinis, Phys. Rev. E 65 (2002) 051602.

[31] B.D. Mather, K. Viswanathan, K.M. Miller, T.E. Long, Prog. Polym. Sci. 31 (2006) 487.

[32] D. Wu, Y. Liu, C. He, T. Chung, S. Goh, Macromolecules 37 (2004) 6763.

[33] C.L. Yaws, Transport Properties of Chemical and Hydrocarbons: Viscosity, Thermal Conductivity, and Diffusivity for more than 7800 Hydrocarbons and Chemicals, Including $C_{1}$ to $C_{100}$ Organics and $A c$ to $\mathrm{Zr}$ Inorganics, William Andrew, New York, 2009.

[34] S.M. Troian, E. Herbolzheimer, S.A. Safran, Phys. Rev. Lett. 65 (1990) 333.

[35] T. Gérard, A. De Wit, Phys. Rev. E 79 (2009) 016308.

[36] C. Almarcha, P.M.J. Trevelyan, P. Grosfils, A. De Wit, Phys. Rev. Lett. 104 (2010) 044501. 